\title{
Research on the Prolonged Effect of Physical Education Class on University Students: Effect Verification of the Intervention Program
}

\author{
Seigo Nakayama', Ryoji Tahara², Kenji Kamino ${ }^{3}$, Kazumasa Marui ${ }^{4}$, Masakazu Watanabe ${ }^{5}$ \\ ${ }^{1}$ Beppu University Junior College, Oita, Japan \\ ${ }^{2}$ Faculty of Human Health, Meio University, Okinawa, Japan \\ ${ }^{3}$ Faculty of Human Development, Toyama University, Toyama, Japan \\ ${ }^{4}$ Faculty of Human Sciences, Kanazawa Seiryo University, Ishikawa, Japan \\ ${ }^{5}$ Faculty of Sports Sciences, Fukuoka University, Fukuoka, Japan \\ Email: seigou@nm.beppu-u.ac.jp
}

Received 6 May 2016; accepted 14 August 2016; published 17 August 2016

Copyright @ 2016 by authors and Scientific Research Publishing Inc.

This work is licensed under the Creative Commons Attribution International License (CC BY). http://creativecommons.org/licenses/by/4.0/

(c) (i) Open Access

\section{Abstract}

The purpose of this study was to verify the prolonged effect of the intervention program on university students in physical education class. Subjects were 211 university students who participated in physical education class. The intervention group is comprised of 81 students (40 males, 41 females), and the control group is comprised of 128 students (80 males, 48 females). All data were obtained through questionnaires. The questionnaires consisted of personal characteristics, skills relating to bachelor's degree ability (communication skill, teamwork skill, problem-solving skill, leadership skill), and exercise behavior (the stage of exercise behavior change, self-efficacy for exercise, decisional balance). The questionnaire data were obtained "at the beginning of the semester (pre)", "at the end of the semester (post)", and "two years after the end of the semester (the two-year follow-up)". Communication program and behavior change skills were applied to the intervention group. The main finding was that the stage of exercise behavior changed in the intervention group. Comparing "pre" with "post", the ratio of students with improved stage was $51.8 \%$; the ratio of students who maintained their stage was $37.3 \%$; and the ratio of students whose stage worsened was $\mathbf{1 0 . 8 \%}$. Additionally, comparing "post" with "the two-year follow-up", the ratio of students with improved stage was 19.3\%; the ratio of students who maintained their stage was 43.4\%; and the ratio of students whose stage worsened was $37.3 \%$. The results of twoway repeated measures ANOVA (group-time) showed that there were significant interactions for 
"perceived benefits of exercise (Pros)", "decoding skill”, "properly transmitted skill”, "teamwork skill", and "leadership skill". The results of one-way repeated measures ANOVA showed that "properly transmitted skill", "teamwork skill", and "leadership skill" significantly increased on account of the intervention program post and at the two-year follow-up. These results indicate that the intervention program on university students, which consists of a communication program and behavior change skills, was partly effective for improving skills relating to bachelor's degree ability two years after the end of semester.

\section{Keywords}

\section{Skills Relating to Bachelor's Degree Ability, The Two-Year Follow-Up, Physical Education Class on University Students, Exercise Behavior}

\section{Introduction}

The goal of physical education in Japanese universities, though varied between universities and courses, can be summarized with key principles such as "acquisition of knowledge and practical skill in lifelong sport", "making exercise a daily habit", "acquisition of physical and mental health", and "improvement of social skill". These goals lead to the "promotion of sport activities in line with the life stages and enrichment of sport opportunities", proposed by the "the Sport Basic Plan" formulated according to the Basic Act on Sport in 2012, the building of "bachelor's degree ability" which is mentioned in "The Structure of Bachelor Degree Education" compiled by the Central Council for Education in 2008 (Ministry of Education, Culture, Sports, Science and Technology, 2008), and the improvement of "Fundamental Competencies for Working Persons", which was put forward by the Ministry of Economy, Trade and Industry in 2006. Thus, a physical education class in university can be said to play a pivotal role in Japanese society.

Consequently, considerable research is also being conducted to examine the impact of university physical education. For example, Hayashi \& Miyamoto (2009) found that a weekly strength training class in university physical education was especially effective for students with no previous experience in such training. Moreover, Kiuchi, Arai, Nakamura \& Urai (2005) and Kiuchi, Arai, Nakamura, Urai \& Hashimoto (2009) suggested that self-monitoring (pleasant feelings/relationship with others/exercise intensity) at the end of a physical education class could increase the benefits of exercise, and "physical education homework" had a positive correlation with the amount of daily exercise undertaken by university students. Similarly, Nakayama, Tahara, Kamino, Marui \& Murakami (2011) showed that the use of behavior change skills in physical education class could affect students' daily exercise behavior. Using a combination of quantitative and qualitative analysis, this study helped clarify the effectiveness of class and provided future direction for the development of teaching material. Especially, when considering implementation of physical education for students in all types of university, it is important to evaluate class through qualitative analysis. While these studies deal with effects on lifelong sport, and the maintenance and improvement of physical fitness as the primary purpose of physical education, Nishida and Hashimoto (2009) revealed that a university physical education program intended for social skill improvement could enhance the "skill of empathy and assistance", while Sugiyama (2008) indicated that physical education could have a partial influence on communication skill. Nakayama, Tahara, Watanabe, Kamino, Marui \& Murakami (2012) further showed that physical education class aimed at "extracurricular learning and activity", "communication among students", and "joy of class participation" could impact general skills as well as attitude and intentionality in bachelor's degree ability.

So far, most interventional studies on university physical education have investigated the effects of intervention programs by comparing "at the beginning of a semester (pre)" and "at the end of a semester (post)"; however, the amount of theses tracking prolonged effect is very limited. For instance, Kiuchi, Arai, Urai \& Nakamura (2006) conducted an interventional class with subsequent follow-up; however as its subjects were only male students investigated three months after the end of semester, there is a need for further investigation. Nakayama, Tahara, Kamino, Marui \& Murakami (2014) explored the sustained effect of the class intervention one year after the end of class through "use of exercise behavior change skills aimed at improvement of exercise be- 
havior, and the communication program aimed at improvement of skills relating to bachelor's degree ability" (the intervention program). The results demonstrated that prolonged effect was evident in exercise behavior, teamwork skill, and leadership skill. The present study is continuation of such studies; our objective was to show a prolonged effect two years after the end of semester (the two-year follow-up).

\section{Methods}

\subsection{Subjects}

Subjects were 209 university students who participated in physical education class. The intervention group comprised 81 students (40 males, 41 females) who participated in the intervention program in 2011 and answered the questionnaire in 2013. The control group comprised 128 students (80 males, 48 females) who did not participate in the intervention program. The departments that the intervention group attended included economics, literature, pharmacy, and technology. The control group belonged to departments of economics, literature, pharmacy, technology, and law.

\subsection{Investigation Period}

Questionnaire data from the intervention group were obtained "at the beginning of the semester (pre) in April, 2011", "at the end of the semester (post) in September, 2011", and "two years after the end of semester (the twoyear follow-up) in November, 2013”. Questionnaire data for the control group were obtained "pre” and "post”. Figure 1 shows the study design.

\subsection{Investigation Contents}

Investigation contents included factors relating to exercise behavior and skills relating to bachelor's degree ability. Factors relating to exercise behavior consisted of the stage of exercise behavior change, self-efficacy for exercise, and decisional balance. Skills relating to bachelor's degree ability consisted of communication skill, teamwork skill, problem-solving skill, and leadership skill. Communication skills consisted of decoding skill, properly transmitted skill, and self-control skill.

\subsection{Measurement Scale}

1) Stage of exercise behavior change

The stage of exercise behavior change scale was defined by the exercise behavior transformation stage scale developed by Oka (2000a) and Oka, Takenaka \& Miyazaki (2000b). Participants were required to choose the most appropriate answer from "Precontemplation (PC)", "Contemplation (C)", "Preparation (PR)", "Action (A)", or "Maintenance (M)". Here, regular exercise was defined as "three times or more per week, and each exercise duration must be 20 min or longer".

2) Self-efficacy for exercise

Self-efficacy for exercise concerns how effective one feels the exercise is, and the scale used here comprises

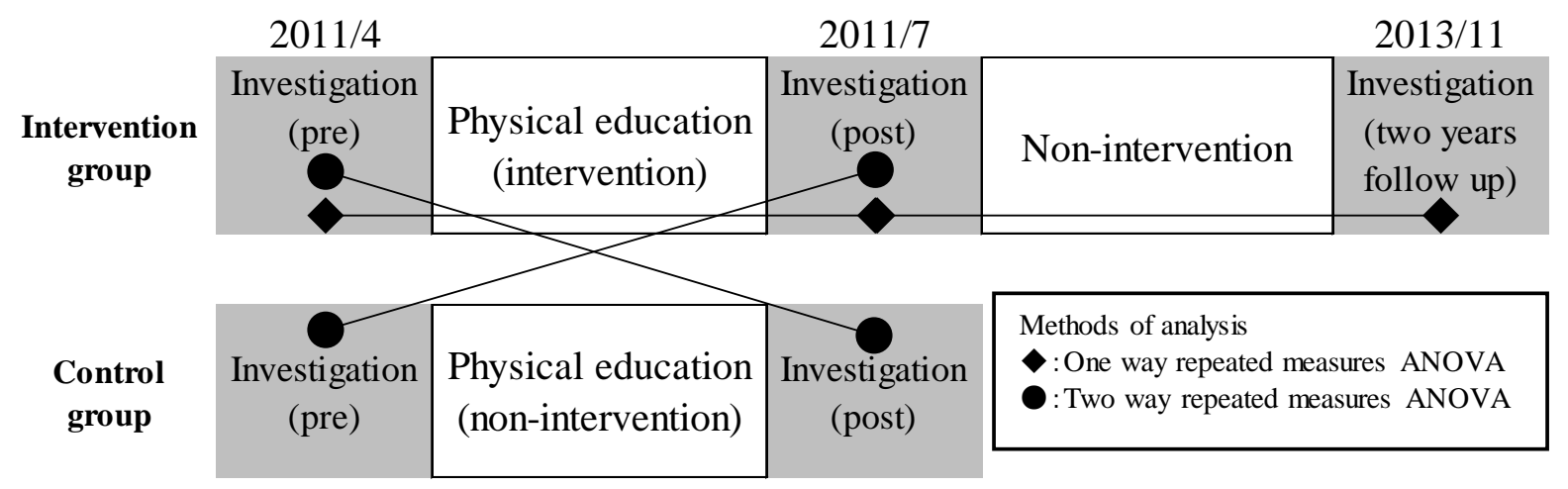

Figure 1. Study design. 
questions associated with the stage of exercise behavior stage developed by Oka (2003). A set of 5 answers, “very much (5 points)”, “so-so (4 points)”, “impossible to say how (3 points)”, "very little (2 points)”, and “not at all (1 point)" were provided for each question; the total points were then calculated. As the questionnaire is made up of four questions, the total points ranged between 4 and 20 .

3) Decisional balance: perceived benefits of exercise (Pros), perceived barriers of exercise (Cons)

Decisional balance was measured by the scale of decisional balance in exercise formulated by Oka, Hirai \& Tsutsumi (2002). It investigated the perceived benefits and barriers toward the execution of exercise. It consisted of 10 benefit questions and 10 barrier questions. The category and method of answers was identical to the aforementioned 5-point system used for measuring self-efficacy for exercise. Hence, the total points ranged between 10 and 50 for both benefits and barriers.

4) Communication skill (Decoding, Properly transmitted, Self-control)

Communication skill was measured using ENDE2, created by Horike (1994). The questionnaire was made up of 13 questions under three categories: “decoding skill (four questions)”, "properly transmitted skill (four questions)", and "self-control skill (five questions)". Each question was provided with a set of five answers: "very capable (5 points)”, “somewhat capable (4 points)”, “impossible to say how (3 points)”, "not very capable (2 points)", and "not at all capable (1 point)". The ranges of total points were decoding skill 4 to 20, properly transmitted skill 4 to 20, and self-control skill 5 to 25 .

5) Teamwork skill, problem-solving skill, leadership skill

Teamwork skill, problem-solving skill, and leadership skill were measured using a section of the sportsspecific positive characteristic scale (ICSS) formulated by Tokunaga \& Hashimoto (2010). There were 14 questions under three categories: "teamwork skill (five questions)”, "problem-solving skill (five questions)", and "leadership skill (four questions)”. A set of five answers was provided for each question: "very applicable (5 points)”, “somewhat applicable (4 points)”, "impossible to say how (3 points)”, "not very applicable (2 points)”, "not at all applicable (1 point)". The ranges of total points were teamwork skill 5 to 25, problem-solving skill 5 to 25, and leadership skill 4 to 20 .

\subsection{Contents of the Intervention Program}

The purpose of this intervention program was to carry out the communication program for the improvement of skills relating to bachelor's degree ability and exercise behavior change skills within class. This was in line with the concepts of "lifelong sport" and "social skill improvement” as main goals of physical education in university. The contents of the intervention program are shown in Table 1 for softball and table tennis activities.

In the first week, the class was divided into the intervention and control groups. In the orientation for the intervention group, the purpose of the research and the contents were explained, and in the both group, a baseline survey was conducted (pre).

In the second week, the communication program started and each student introduced themselves. From the third week onward, all students had to call out each other by their self-elected nicknames (nicknames seal). As an icebreaker, the first 10 min of the class was used for activities aimed at "cooperation”, "touch”, and "competition" (recreation). Although methods differed by activity type, the points of the same sort were assigned for each icebreaking activity.

The contents of exercise behavior change skills were carried out through "target setting (pedometer)", "self-monitoring”, “cognitive intervention”, “feedback” and "physical education homework”. Exercise behavior change skills were performed from the third week by attaching a pedometer (calorie counter, Suzuken) to each student throughout the classduration. The number of steps recorded (record of the third week) was then used as a reference, and the target number of the steps in the class was set (target setting). From the fourth to 13th week, the students had to record the number of steps taken on a record sheet (self-monitoring), and then give intermediate feedback on the eighth week. Appraisal was given to subjects who achieved the target (operant reinforcement), while subjects who failed to achieve the target considered reasons for failure and possible improvement measures (barrier removal). In addition, “the physical education homework” (Kiuchi, Arai, Nakamura, \& Urai, 2005) and the cognitive intervention (daily physical activity, flexibility, overall endurance, strength/strength endurance) were conducted between the 10th and 13th weeks. Explanation for the cognitive intervention was given during the last $10 \mathrm{~min}$ of the class.

A survey was conducted on the 14th week (post) and the results were fed back on the 15th week. 
Table 1. The contents of the intervention program (softball/table tennis).

\begin{tabular}{|c|c|c|c|}
\hline & Activity & Communication program & Exercise behavior change skills \\
\hline 1 & & Class division, orientation & \\
\hline 2 & Softball & Self-introduction & \\
\hline 3 & Softball & $\begin{array}{l}\text { Human disentanglement puzzle } \\
\text { dub to each other by self-elected nicknames }\end{array}$ & Target setting (pedometer) \\
\hline 4 & Softball & $\begin{array}{l}\text { Hula-hoop recreation } \\
\text { dub to each other by self-elected nicknames }\end{array}$ & Self-monitoring \\
\hline 5 & Softball & $\begin{array}{c}\text { Chain tag } \\
\text { dub to each other by self-elected nicknames }\end{array}$ & Self-monitoring \\
\hline 6 & Softball & $\begin{array}{c}\text { Chain tag (duo) } \\
\text { dub to each other by self-elected nicknames }\end{array}$ & Self-monitoring \\
\hline 7 & Softball & $\begin{array}{c}\text { Match } \\
\text { dub to each other by self-elected nicknames }\end{array}$ & Self-monitoring \\
\hline 8 & Softball & $\begin{array}{c}\text { Match } \\
\text { dub to each other by self-elected nicknames }\end{array}$ & $\begin{array}{c}\text { Feedback } \\
\text { operant reinforcement } \\
\text { barrier removal }\end{array}$ \\
\hline 9 & Table tennis & $\begin{array}{l}\text { Table tennis recreation (one minute measurement by duo) } \\
\text { dub to each other by self-elected nicknames }\end{array}$ & $\begin{array}{l}\text { Target setting (pedometer) } \\
\text { self-monitoring }\end{array}$ \\
\hline 10 & Table tennis & $\begin{array}{l}\text { Table tannis recreation (one minute measurement by foursome) } \\
\text { dub to each other by self-elected nicknames }\end{array}$ & Self-monitoring \\
\hline 11 & Table tennis & $\begin{array}{l}\text { Table tannis recreation } \\
\text { (one minute measurement by duo and foursome) } \\
\text { dub to each other by self-elected nicknames }\end{array}$ & $\begin{array}{l}\text { Self-monitoring } \\
\text { physical education homework } \\
\text { cognitive intervention }\end{array}$ \\
\hline 12 & Table tennis & $\begin{array}{l}\text { Table tannis recreation (word chain) } \\
\text { dub to each other by self-elected nicknames }\end{array}$ & $\begin{array}{l}\text { Self-monitoring } \\
\text { physical education homework } \\
\text { cognitive intervention }\end{array}$ \\
\hline 13 & Table tennis & $\begin{array}{l}\text { Walk blindhold } \\
\text { dub to each other by self-elected nicknames }\end{array}$ & $\begin{array}{l}\text { Self-monitoring } \\
\text { physical education homework } \\
\text { cognitive intervention }\end{array}$ \\
\hline 14 & Table tennis & $\begin{array}{l}\text { Table tannis recreation (hit at PET bottle) } \\
\text { dub to each other by self-elected nicknames }\end{array}$ & $\begin{array}{c}\text { Physical education homework } \\
\text { cognitive intervention } \\
\text { feedback } \\
\text { operant reinforcement }\end{array}$ \\
\hline 15 & Table tennis & $\begin{array}{c}\text { Match } \\
\text { dub to each other by self-elected nicknames }\end{array}$ & \\
\hline
\end{tabular}

\subsection{Ethical Consideration}

This study received the approval of the Ethical Review Board of the university (approval number 131103).

Before the study, we explained the purpose to all subjects and informed them that the collected data would be processed statistically and used for research purposes only. We took measurements from those who provided consent.

\section{Results and Discussion}

\subsection{The Stage of Exercise Behavior Change}

To demonstrate the effect of the intervention on the stage of exercise behavior change and its continuity, a cross tabulation of the stage of exercise behavior change at "pre and post" and "post and the two-year follow-up" was conducted. The results are shown in Tables 2-5. The number of students who maintained the stage of exercise behavior change in both "pre and post" and "post and the two-year follow-up" (stay) is indicated by shaded areas. The upper right-hand side of the shaded areas represents the number of students who had improved in stage (up), while the lower left-hand side represents students who declined in stage (down) (Table 2 and Table 4). Observing the ratio of transformation in the stage of exercise behavior change, we found that "from pre to post semester", 41 out of 81 students were "up" (50.6\%), 31 out of 81 were "stay" at the same position (38.3\%), and 9 out 
Table 2. Change in the stage of exercise behavior (pre-post).

\begin{tabular}{|c|c|c|c|c|c|c|}
\hline Total (number) & & & & & & \\
\hline Males (number) & PC & $\mathrm{C}$ & $\mathrm{P}$ & A & M & Number (\%) \\
\hline \multicolumn{7}{|l|}{ Females (number) } \\
\hline \multirow{3}{*}{ PC } & 6 & 4 & 4 & 2 & 0 & $16(19.8)$ \\
\hline & 2 & 3 & 0 & 0 & 0 & 5 (12.5) \\
\hline & 4 & 1 & 4 & 2 & 0 & $11(26.8)$ \\
\hline \multirow{3}{*}{$\mathrm{C}$} & 3 & 12 & 18 & 8 & 0 & $41(50.6)$ \\
\hline & 0 & 6 & 8 & 3 & 0 & 17 (42.5) \\
\hline & 3 & 6 & 10 & 5 & 0 & 24 (58.5) \\
\hline \multirow{3}{*}{$\mathrm{P}$} & 0 & 2 & 7 & 2 & 0 & 11 (13.6) \\
\hline & 0 & 2 & 4 & 1 & 0 & 7 (17.5) \\
\hline & 0 & 0 & 3 & 1 & 0 & $4(9.8)$ \\
\hline \multirow{3}{*}{ A } & 0 & 0 & 1 & 4 & 3 & $8(9.9)$ \\
\hline & 0 & 0 & 1 & 2 & 3 & $6(15.0)$ \\
\hline & 0 & 0 & 0 & 2 & 0 & $2(4.9)$ \\
\hline \multirow{3}{*}{ M } & 0 & 0 & 3 & 0 & 2 & $5(6.2)$ \\
\hline & 0 & 0 & 3 & 0 & 2 & 5 (12.5) \\
\hline & 0 & 0 & 0 & 0 & 0 & $0(0.0)$ \\
\hline \multirow{3}{*}{ Number (\%) } & $9(11.1)$ & $18(22.2)$ & $33(40.7)$ & $16(19.8)$ & $5(6.2)$ & 81 \\
\hline & $2(5.0)$ & $11(27.5)$ & $16(40.0)$ & $6(15.0)$ & $5(12.5)$ & 40 \\
\hline & 7 (17.1) & 7 (17.1) & 17 (41.5) & $10(24.4)$ & $0(0.0)$ & 41 \\
\hline
\end{tabular}

Table 3. Ratio of change in exercise behavior (pre-post).

\begin{tabular}{ccccc}
\hline & up & stay & down & total \\
\hline Total & 41 & 31 & 9 & 81 \\
$(\%)$ & 50.6 & 38.3 & 11.1 & 100.0 \\
Males & 18 & 16 & 6 & 40 \\
$(\%)$ & 45.0 & 40.0 & 15.0 & 100.0 \\
Females & 23 & 15 & 3 & 41 \\
$(\%)$ & 56.1 & 36.6 & 7.3 & 100.0 \\
\hline
\end{tabular}

of 81 were “down” (11.1\%) (Table 3). “From post to the two-year follow-up”, 16 out of 81 students were “up” (19.8\%), 34 out of 81 were "stay” at the same position (42.0\%), and 31 out of 81 were “down” (38.3\%) (Table 5).

As a result of the intervention program, the ratio of students who maintained or improved in the stage from pre to post amounted to $88.9 \%$. However, from post to the two-year follow-up, the ratio of students who had declined in stage had risen to almost 40\% (38.3\%). According to research on the exercise habits of 361 third-year university students carried out by Marui, Tahara, Nakayama, Kamino \& Murakami (2011), the ratios of stage of exercise behavior change are "precontemplation” 26.9\%, “contemplation” 13.9\%, "preparation” 35.5\%, “action” $4.7 \%$, and "maintenance" $19.1 \%$. In comparison with the results of the present research in which students attended the intervention program, even though the ratio of "precontemplation” declined, the ratio of "contemplation" increased, while that of "maintenance” decreased. Furthermore, previous research that investigated conditions one year after the completion of physical education class (Nakayama, Tahara, Kamino, Marui, \& Murakami, 2014) showed that the ratio of students who were able to maintain or improve in stage was $72.1 \%$, which is higher than the results of the current study. This suggests that the interventional effects on the stage of exercise behavior change after two years may be minimal. 
Table 4. Change in the stage of exercise behavior (post the two-year follow-up).

\begin{tabular}{|c|c|c|c|c|c|c|}
\hline Total (number) & & & & & & \\
\hline Males (number) & PC & $\mathrm{C}$ & $\mathrm{P}$ & A & M & Number (\%) \\
\hline \multicolumn{7}{|l|}{ Females (number) } \\
\hline \multirow{3}{*}{ PC } & 7 & 1 & 1 & 0 & 0 & 9 (11.1) \\
\hline & 1 & 1 & 0 & 0 & 0 & $2(5.0)$ \\
\hline & 6 & 0 & 1 & 0 & 0 & 7 (17.1) \\
\hline \multirow{3}{*}{$\mathrm{C}$} & 2 & 9 & 5 & 2 & 0 & $18(22.2)$ \\
\hline & 2 & 5 & 2 & 2 & 0 & $11(27.5)$ \\
\hline & 0 & 4 & 3 & 0 & 0 & 7 (17.1) \\
\hline \multirow{3}{*}{$\mathrm{P}$} & 3 & 10 & 16 & 3 & 1 & 33 (40.7) \\
\hline & 0 & 5 & 10 & 1 & 0 & $16(40.0)$ \\
\hline & 3 & 5 & 6 & 2 & 1 & 17 (41.5) \\
\hline \multirow{3}{*}{ A } & 1 & 5 & 6 & 1 & 3 & $16(19.8)$ \\
\hline & 0 & 2 & 3 & 0 & 1 & $6(15.0)$ \\
\hline & 1 & 3 & 3 & 1 & 2 & $10(24.4)$ \\
\hline \multirow{3}{*}{ M } & 0 & 0 & 4 & 0 & 1 & $5(6.2)$ \\
\hline & 0 & 0 & 4 & 0 & 1 & 5 (12.5) \\
\hline & 0 & 0 & 0 & 0 & 0 & $0(0.0)$ \\
\hline \multirow{3}{*}{ Number (\%) } & $13(16.0)$ & 25 (30.9) & 32 (39.5) & $6(7.4)$ & $5(6.2)$ & 81 \\
\hline & $3(7.5)$ & $13(32.5)$ & $19(47.5)$ & $3(7.5)$ & $2(5.0)$ & 40 \\
\hline & $10(24.4)$ & $12(29.3)$ & 13 (31.7) & $3(7.3)$ & $3(7.3)$ & 41 \\
\hline
\end{tabular}

Table 5. Ratio of change in exercise behavior (post the two-year follow-up).

\begin{tabular}{ccccc}
\hline & Up & Stay & Down & Total \\
\hline Total & 16 & 34 & 31 & 81 \\
$(\%)$ & 19.8 & 42.0 & 38.3 & 100.0 \\
Males & 7 & 17 & 16 & 40 \\
$(\%)$ & 17.5 & 42.5 & 40.0 & 100.0 \\
Females & 9 & 17 & 15 & 41 \\
$(\%)$ & 22.0 & 41.5 & 36.6 & 100.0 \\
\hline
\end{tabular}

\subsection{Self-Efficacy for Exercise, Perceived Benefits of Exercise (Pros), Perceived Barriers of Exercise (Cons)}

The results of both the intervention and control groups from pre to post are shown in Table 6. The results of self-efficacy for exercise and decisional balance for the intervention group from pre to the two-year follow-up are shown in Table 7. When using two-way repeated measures ANOVA to examine the interaction between time (pre to post) and group (intervention and control), a correlation with perceived benefits of exercise (Pros) was also observed. However, when one-way repeated measures ANOVA was used to examine the results from pre, post, and the two-year follow-up, no significant difference could be observed in all categories.

This result indicates that from pre to post, the interventional effect on perceived benefits of exercise (Pros) could be observed in the intervention group but that this effect had diminished after two years. Kiuchi, Arai, Nakamura, Urai \& Hashimoto (2009) reported that in university physical education, the perceived benefits of exercise (Pros) significantly increased with the intervention of self-monitoring; the results of this study concurred with such findings at the end of the semester. However, this effect did not last until the two-year follow-up. In a previous study (Nakayama, Tahara, Kamino, Marui, \& Murakami, 2014), the sustained effect on 
Table 6. Change in exercise behavior and skills relating to bachelor's degree ability (group-time, two-way repeated measures ANOVA).

\begin{tabular}{|c|c|c|c|c|c|c|c|c|c|c|}
\hline \multirow{4}{*}{ Item } & \multirow{2}{*}{\multicolumn{4}{|c|}{$\begin{array}{c}\text { Intervention group }(\mathrm{n}=81) \\
\text { Males: } 40 \text {, females: } 41\end{array}$}} & \multirow{2}{*}{\multicolumn{4}{|c|}{$\begin{array}{l}\text { Control group }(\mathrm{n}=128) \\
\text { Males: } 80 \text {, females: } 48\end{array}$}} & \multirow{4}{*}{ Time } & \multirow{4}{*}{ Interactior } \\
\hline & & & & & & & & & & \\
\hline & \multicolumn{2}{|c|}{ Pre } & \multicolumn{2}{|c|}{ Post } & \multicolumn{2}{|c|}{ Pre } & \multicolumn{2}{|c|}{ Post } & & \\
\hline & M & SD & M & SD & M & SD & M & SD & & \\
\hline Self-efficacy for exercise & 11.7 & 3.5 & 12.7 & 3.2 & 11.2 & 3.4 & 12.3 & 4.0 & $p<.01$ & n.s. \\
\hline Perceived benefits of exercise (Pros) & 36.3 & 5.4 & 37.9 & 4.8 & 36.3 & 5.2 & 36.5 & 5.0 & $p<.01$ & $p<.05$ \\
\hline Perceived barriers of exercise (Cons) & 22.3 & 4.6 & 22.9 & 5.7 & 23.3 & 4.9 & 25.0 & 6.2 & $p<.01$ & n.s. \\
\hline \multicolumn{11}{|l|}{ Communication skill } \\
\hline Decoding skill & 13.9 & 2.6 & 14.6 & 2.5 & 14.1 & 2.8 & 14.1 & 2.7 & $p<.05$ & $p<.05$ \\
\hline Properly-transmit skill & 13.0 & 2.2 & 14.0 & 2.2 & 13.1 & 2.5 & 13.4 & 2.6 & $p<.01$ & $p<.05$ \\
\hline Self-control skill & 16.6 & 2.8 & 16.5 & 2.5 & 17.0 & 2.1 & 17.3 & 2.4 & n.s. & n.s. \\
\hline Teamwork skill & 17.5 & 2.8 & 18.6 & 2.6 & 17.3 & 3.2 & 17.5 & 3.5 & $p<.01$ & $p<.05$ \\
\hline Problem-solving skill & 17.4 & 3.5 & 18.2 & 3.8 & 17.6 & 3.5 & 18.2 & 3.3 & $p<.01$ & n.s. \\
\hline Leadership skill & 11.0 & 3.0 & 12.6 & 2.9 & 11.2 & 3.0 & 12.0 & 3.2 & $p<.01$ & $p<.05$ \\
\hline
\end{tabular}

Table 7. Change in exercise behavior and skills relating to bachelor's degree ability (intervention group, one-way repeated measures ANOVA).

\begin{tabular}{|c|c|c|c|c|c|c|c|c|c|}
\hline \multirow{4}{*}{ Item } & \multicolumn{6}{|c|}{ Intervention group $(\mathrm{n}=81)$} & \multirow{2}{*}{\multicolumn{3}{|c|}{ One-way repeated measures ANOVA }} \\
\hline & \multicolumn{6}{|c|}{ Males: 40, Females: 41} & & & \\
\hline & \multicolumn{2}{|c|}{ Pre } & \multicolumn{2}{|c|}{ Post } & \multicolumn{2}{|c|}{$2 \mathrm{yfu}^{\dagger}$} & \multirow[b]{2}{*}{$\mathrm{F}$} & & \multirow[b]{2}{*}{ Dunnet } \\
\hline & $\mathrm{M}$ & SD & $\mathrm{M}$ & SD & M & SD & & & \\
\hline Self-efficacy for exercise & 11.7 & 3.5 & 12.7 & 3.2 & 12.0 & 3.3 & 1.87 & & \\
\hline Perceived benefits of exercise (Pros) & 36.3 & 5.4 & 37.9 & 4.8 & 37.6 & 4.7 & 2.50 & & \\
\hline Perceived barriers of exercise (Cons) & 22.3 & 4.6 & 22.9 & 5.7 & 23.4 & 5.1 & 0.90 & & \\
\hline \multicolumn{10}{|l|}{ Communication skill } \\
\hline Decoding skill & 13.9 & 2.6 & 14.6 & 2.5 & 14.5 & 2.2 & 2.02 & & \\
\hline Properly-transmit skill & 13.0 & 2.2 & 14.0 & 2.2 & 14.1 & 2.4 & 5.33 & ** & Pre $<$ post, 2yfu \\
\hline Self-control skill & 16.6 & 2.8 & 16.5 & 2.5 & 16.3 & 3.1 & 0.17 & & \\
\hline Teamwork skill & 17.5 & 2.8 & 18.6 & 2.6 & 18.7 & 3.1 & 4.00 & * & Pre < post, 2yfu \\
\hline Problem-solving skill & 17.4 & 3.5 & 18.2 & 3.8 & 18.3 & 3.1 & 1.53 & & \\
\hline Leadership skill & 11.0 & 3.0 & 12.6 & 2.9 & 12.9 & 3.1 & 9.55 & ** & Pre $<$ post, 2yfu \\
\hline
\end{tabular}

${ }^{\dagger} 2$ yfu: two years follow up.

perceived benefits of exercise (Pros) one year after the completion of the physical education class had already been demonstrated. It might be possible to hypothesize that the effect of the intervention program may diminish one to two years after the end of the semester.

\subsection{Communication Skill (Decoding, Properlytransmitted, Self-Control)}

A correlation could be seen between decoding skill and properly transmitted skill when using two-way repeated measures ANOVA to analyze results (Table 6). Moreover, when analyzing properly transmitted skill with oneway repeated measures ANOVA, the figure revealed was significantly higher at post and the two-year follow-up compared with pre (Table 7).

This suggests that the communication program intervention used in this research had a prolonged effect on properly transmitted skill, which is a type of communication skill, not only at the end of the semester but also 
two years following the end of the semester. In contrast, for the decoding skill, an effect was observed at the end of a semester, but it subsided at the two-year follow-up. Sugiyama's (2008) study did not use any special intervention to improve communication skill. Instead, he used ENDE2, as did this research, to investigate the transformation from pre to post university physical education class but found no significant change in all three skills. In other words, this research had also demonstrated the necessity of icebreaking activities such as self-introduction or calling out by self-elected nicknames in which students must actively participate in communication instead of merely playing team sports in university physical education class, which is aimed at improving communication skill.

\subsection{Teamwork Skill, Problem-Solving Skill, Leadership Skill}

The results of the two-way repeated measures ANOVA showed a correlation between teamwork skill and leadership skill $(p<.05)$ (Table 6). The figures for teamwork skill $(p<.05)$ and leadership skill $(p<.01)$ were both significantly higher at the end of the semester and the two-year follow-up than pre when using the one-way repeated measures ANOVA (Table 7).

This suggests that the intervention program was effective in the cultivation of teamwork skill and leadership skill as its impact persisted for two years following the end of the semester. According to Pauline and John (1995), the factors influencing teamwork are team objectives, team targets, and communication. In the present research, the goal of improving skills relating to bachelor's degree ability and promoting exercise behavior was made clear to the intervention group. The programs aimed at encouraging communication between students in class were also implemented, leading to the improvement of teamwork skill. In addition, Nakayama, Tahara, Watanabe, Kamino, Marui \& Murakami (2012) reported that "extracurricular learning/activity", "communication among students", and "joy of class participation" all contributed to the improvement of leadership skill; similar results were also derived in this research. Regarding the fact that no significant increase in could be observed in problem-solving skill, a review of question items showed that students made remarks such as "Even when problems or difficulties arise, I am able to tackle things tenaciously in order to overcome them", and "Even when faced with adversity or predicament, I am able to tackle things patiently without losing myself". The students who participated in the intervention program did not seem to experience any problematic situations, i.e., situations that might be described as difficult, involving adversity or a predicament. A diminished effect could therefore be understood as the result of a lack of opportunity for problem solving.

\section{Conclusion}

The intervention program, which aimed at "acquisition of fitness habits" and "improvement of skills relating to bachelor's degree ability" was effective at the post-semester follow-up. However, at the two-year follow-up, only "skills relating to bachelor's degree ability" were improved.

\section{Limitations and Issues in This Research}

Three issues and limitations apply to this research. First, the sample of this study was limited to one university; hence, the generalizability of the results is unclear. Future investigation will need to increase the number of universities utilized to provide study subjects and take into account variation in environment, such as locality, gender and faculty. Second, the setting for the control group was insufficient. Originally, the examination of the control group should not be limited to pre and post semester but should also be set at the two-year follow-up to correspond with the intervention group. To more accurately reveal the intervention effect, future research ought to take this into account. Finally, besides the two-year follow-up, a longitudinal study that continues to examine the effect at three years from the end of semester and even post-graduation is desirable.

\section{Acknowledgements}

This work was supported by the grant of the Beppu University GP (study support) in 2013.

\section{References}

Hayashi, N., \& Miyamoto, M. (2009). Effect of Resistance Training at a Frequency of Once a Week on Muscular Strength in 
College Students. Japan Journal of Physical Education, Health and Sport Sciences, 54, 137-143. http://dx.doi.org/10.5432/jipehss.a540114

Horike, K. (1994). The Refinement of Heterosocial Skills through the Development and Deterioration in Close Interpersonal Relationships. The Japanese Journal of Experimental Social Psychology, 34, 116-128. http://dx.doi.org/10.2130/jjesp.34.116

Kiuchi, A., Arai, H., Nakamura, T., \& Urai, R. (2005). Effects of Physical Education Homework on the Amount of Daily Physical Activity and the Health-Related Fitness of University Freshmen. Japanese Journal of Sport Education Studies, 25, 1-9. http://dx.doi.org/10.7219/jjses.25.1

Kiuchi, A., Arai, H., Nakamura, T., Urai, R., \& Hashimoto, K. (2009). Effects of Self-Monitoring at the End of a Physical Education Class on the Decisional Balance for Exercise and the Level of Physical Activity. Japan Journal for Health, Physical Education, Recreation, and Dance in Universities, 6, 3-11.

Kiuchi, A., Arai, H., Urai, R., \& Nakamura, T. (2006). Physical Activity Enhancement among Japanese College Freshmen through the Concept of "Physical Activity Pyramid" and Behavior Change Skills. Japan Journal for Health, Physical Education, Recreation, and Dance in Universities, 3, 3-14.

Marui, K., Tahara, R., Nakayama, S., Kamino, K., \& Murakami, I. (2011). The Relationship between the Factors in the Physical Education Class Composition and Exercise Habit after the Class Term: Through Investigation of Each School Year. Japan Journal for Health, Physical Education, Recreation, and Dance in Universities, 8, 65-73.

Ministry of Education, Culture, Sports, Science and Technology (2008). The Structure of Bachelor Degree Education (Report), Central Council for Education.

Nakayama, S., Tahara, R., Kamino, K., Marui, K., \& Murakami, I. (2011). The Effect of Behavioral Intervention in Physical Education Class on Daily Exercise Behavior in University. Educational Journal of Health, Sport and Physical Education, 11, 14-22.

Nakayama, S., Tahara, R., Kamino, K., Marui, K., \& Murakami, I. (2014). Research on Long-Term Effect of Physical Education Intervention for University Students: Focusing on One Year Follow up of Skills Relating to Bachelor's Degree Ability and Exercise Behavior. Japan Journal for Health, Physical Education, Recreation, and Dance in Universities, 11, 65-78.

Nakayama, S., Tahara, R., Watanabe, M., Kamino, K., Marui, K., \& Murakami, I. (2012). A Study on the Effect of the Physical Education Class at University on a Bachelor's Degree Capacity: Focusing on Generic Skills, Attitude and Intention. Bulletin of Beppu University Junior College, 31, 45-51.

Nishida, J., \& Hashimoto, K. (2009). The Psychosocial Effect of Physical Education Program Intend to Improvement and Enhancement Social Skills for First Year University Students. Japan Journal for Health, Physical Education, Recreation, and Dance in Universities, 6, 91-99.

Oka, K. (2000a). Recent Trends of Research on Exercise Adherence Utilizing the Transtheoretical Model of Behavior Change. Japan Journal of Physical Education, Health and Sport Sciences, 45, 543-561.

Oka, K. (2003). Stages of Change for Exercise Behavior and Self-Efficacy for Exercise among Middle-Aged Adults. Japanese Journal of Public Health, 50, 208-215.

Oka, K., Hirai, K., \& Tsutsumi, T. (2002). Psychological Factors Associated with Physical Inactivity among Middle-Aged Adults: Decisional Balance for Exercise. Japanese Journal of Behavioral Medicine, 9, 23-30.

Oka, K., Takenaka, K., \& Miyazaki, Y. (2000b). Assessing the Stage of Change for Exercise Behavior among Young Adults: The Relationship with Self-Reported Physical Activity and Exercise Behavior. Japanese Health Psychology, 8, 17-23.

Pauline, P., \& John, S. (1995). Pointers to Effective Teamwork: Exploring Primary Care. Journal of Interprofessional Care, 9, 131-138. http://dx.doi.org/10.3109/13561829509047847

Sugiyama, Y. (2008). Possibility for the Improvement of Communication Skills through Sport in Physical Education in University. Japan Journal for Health, Physical Education, Recreation, and Dance in Universities, 5, 3-11.

Tokunaga, T., \& Hashimoto, K. (2010). Development of the Creative Physical Education Program That Can Cope with the Mental and Physical Health Problem for the University Student Based on the Behavioral Science. Grant-in-Aid Scientific Research Subsidy in 2009-2011 (B), Interim Report of Results of Research in 2009, 71-72. 


\section{Submit or recommend next manuscript to SCIRP and we will provide best service for you:}

Accepting pre-submission inquiries through Email, Facebook, LinkedIn, Twitter, etc.

A wide selection of journals (inclusive of 9 subjects, more than 200 journals)

Providing 24-hour high-quality service

User-friendly online submission system

Fair and swift peer-review system

Efficient typesetting and proofreading procedure

Display of the result of downloads and visits, as well as the number of cited articles

Maximum dissemination of your research work

Submit your manuscript at: http://papersubmission.scirp.org/ 